\title{
Outcomes in patients with atypical hemolytic uremic syndrome treated with eculizumab in a long-term observational study
}

Jan Menne ${ }^{1 *}$, Yahsou Delmas ${ }^{2}$, Fadi Fakhouri ${ }^{3}$, Christoph Licht ${ }^{4}$, Åsa Lommelée ${ }^{5}$ Enrico E. Minetti ${ }^{6}$, François Provôt ${ }^{7}$, Eric Rondeau ${ }^{8,9}$, Neil S. Sheerin ${ }^{10}$, Jimmy Wang ${ }^{11}$, Laurent E. Weekers ${ }^{12}$ and Larry A. Greenbaum ${ }^{13}$

\begin{abstract}
Background: There are limited long-term outcome data in eculizumab-treated patients with atypical hemolytic uremic syndrome (aHUS). We report final results from the largest prospective, observational, multicenter study of patients with aHUS treated with eculizumab.

Methods: Patients with aHUS who participated in any of five parent eculizumab trials and received at least one eculizumab infusion were eligible for enrollment in a long-term follow-up study. Rates of thrombotic microangiopathy (TMA) manifestations off versus on eculizumab were evaluated. Additional endpoints included change from baseline estimated glomerular filtration rate (eGFR), long-term renal outcomes, and serious targeted treatment-emergent adverse events.

Results: Among 93 patients (0-80 years of age), 51 (55\%) remained on eculizumab and 42 (45\%) discontinued; for those who discontinued, 21 (50\%) reinitiated therapy. Patients who reinitiated eculizumab had similar baseline clinical characteristics to patients who remained on eculizumab, with higher likelihood of genetic/autoimmune complement abnormalities, more prior TMAs, and longer disease course versus those who did not reinitiate. Mean eGFR improved rapidly and remained stable for up to 6 years on eculizumab. In patients who discontinued, there was a trend toward decreasing renal function over time from discontinuation. Additionally, off-treatment TMA manifestation rates were higher in those aged $<18$ years at diagnosis, with identified genetic/autoimmune complement abnormalities, or history of multiple TMAs prior to eculizumab initiation. The safety profile was consistent with previous studies. Three definite and one possible meningococcal infections related to eculizumab were reported and resolved with treatment. Three deaths unrelated to eculizumab were reported.

Conclusions: The current study confirms the efficacy and safety of eculizumab in aHUS, particularly with regard to long-term renal function and TMA events. Pediatric age at disease onset and presence of genetic or autoimmune complement abnormalities are risk factors for TMA events off treatment. Overall, patients who discontinue eculizumab may be at risk for additional TMA manifestations and renal function decreases. Discontinuation of eculizumab, with careful monitoring, is an option in select patients with consideration of patient preference, organ function normalization, and risk factors for relapse, including mutational analysis, age of onset, and history of multiple TMA episodes.
\end{abstract}

Trial registration: ClinicalTrials.gov NCT01522170, January 31, 2012.

Keywords: Atypical hemolytic uremic syndrome, Alternate complement pathway, Eculizumab, Thrombotic microangiopathy

\footnotetext{
* Correspondence: menne.jan@mh-hannover.de

${ }^{1}$ Department of Nephrology and Hypertension, Klinik für Nieren- und

Hochdruckerkrankungen, Carl Neuberg Str. 1, 30625 Hannover, Germany

Full list of author information is available at the end of the article
}

(c) The Author(s). 2019 Open Access This article is distributed under the terms of the Creative Commons Attribution 4.0 International License (http://creativecommons.org/licenses/by/4.0/), which permits unrestricted use, distribution, and reproduction in any medium, provided you give appropriate credit to the original author(s) and the source, provide a link to the Creative Commons license, and indicate if changes were made. The Creative Commons Public Domain Dedication waiver (http://creativecommons.org/publicdomain/zero/1.0/) applies to the data made available in this article, unless otherwise stated. 


\section{Background}

Atypical hemolytic uremic syndrome (aHUS) is a rare disorder caused by overactivation of the alternative pathway of complement and is primarily characterized by thrombotic microangiopathy (TMA) [1, 2]. Classic manifestations include thrombocytopenia, microangiopathic hemolytic anemia, and acute kidney injury, although other organs are often also affected. During the era when plasma infusion or plasma exchange was the mainstay of management, aHUS was associated with a poor prognosis. Historically, $36 \%$ of children and $64 \%$ of adults developed end-stage renal disease or died within 3 to 5 years of disease onset [3].

Eculizumab (Soliris ${ }^{\oplus}$ Alexion Pharmaceuticals, Inc., Boston, MA, USA) is a humanized monoclonal complement inhibitor that is the first and only approved treatment for patients with aHUS $[4,5]$. Eculizumab binds with high affinity to $\mathrm{C} 5$, inhibiting $\mathrm{C} 5$ cleavage to $\mathrm{C} 5 \mathrm{a}$ and $\mathrm{C} 5 \mathrm{~b}$ and preventing the generation of the terminal complement complex C5b-9, thus inhibiting complement-mediated TMA. Eculizumab was proven to be effective in patients with aHUS in five clinical studies [6-10], in which it resolved and prevented complement-mediated TMA, improving renal function and hematologic outcomes.

Optimal duration of eculizumab therapy in aHUS has not yet been determined. The potential risk of developing TMA following discontinuation of treatment $[4,5]$ and the recommendation of lifelong treatment [5] have been noted in current regulatory guidance. We conducted a large prospective, long-term, observational study of patients with aHUS who were treated with eculizumab. Data from an interim analysis (cutoff date: March 28, 2015; median exposure, 45.9 months) showed a lower rate of TMA manifestations in patients who were receiving eculizumab versus patients who were not on therapy [11]. Here, we report the final results from this study.

\section{Methods}

\section{Study design and patient population}

This was a long-term, prospective, observational, multicenter follow-up study (NCT01522170) of patients with aHUS who were treated with at least one infusion of eculizumab in any of five previously conducted parent studies, several of which included pediatric and/or adolescent patients < 18 years of age [6-10] (Fig. 1).

Study methodology has been published previously [11], but is summarized in brief herein. Participating patients received meningococcal vaccination in the parent eculizumab trials $[6,8,9]$ and were revaccinated according to their respective country guidelines. Use of antibiotic prophylaxis was not required per the study protocol but was permitted at the investigators' discretion. Assessment of genetic and autoimmune complement abnormalities was performed in all patients upon entry into the parent studies by a centralized laboratory and was not repeated during the current study.

Baseline characteristics were recorded before the first infusion of eculizumab in the parent studies. In the parent studies, patients were administered eculizumab as per the dosing schedule described in the prescribing information. Patients were enrolled in the current study at the completion of the parent study. During the current study, changes in dosage and treatment duration were permitted at the investigators' discretion. Clinical outcomes were compared based on eculizumab treatment status.

The first on-treatment period was defined as the date from the first infusion through 3 weeks after the last eculizumab infusion, or until patient discontinuation from the study or data cutoff (whichever occurred first). The first off-treatment period was from 3 weeks after the last infusion of eculizumab until the patient restarted eculizumab, or until patient discontinuation from the study or data cutoff (whichever occurred first). Subsequent on- and off-treatment periods were defined similarly and patient groups were not mutually exclusive.

\section{Study endpoints and analysis}

The primary study endpoint was the rate of TMA manifestations in the current study during off and on treatment. The criteria used to define TMA are described in Table 1 [11]. Additional endpoints included change in renal function, long-term renal outcomes, and assessment of serious targeted treatment-emergent adverse events (TEAEs). Post hoc analyses were conducted to evaluate the TMA manifestation rate by comparing offand on-treatment periods in the current study. Rates were also compared based on patient characteristics, including identified genetic or autoimmune complement abnormalities, age, history of TMA events, and transplant status.

Changes in renal function were measured using estimated glomerular filtration rate (eGFR). For patients who remained on eculizumab throughout the study, eGFR was compared between values determined 6 months after the initiation of eculizumab and last follow-up. For patients who discontinued eculizumab, eGFR was compared immediately prior to discontinuation and at last follow-up. For patients who discontinued but later reinitiated eculizumab, eGFR was compared immediately prior to discontinuation and at last follow-up after eculizumab reinitiation. Patients were not included in the analysis if these data were unavailable. Renal outcomes for individual patients were assessed independently by the principal investigator and two additional investigators, and reported as improved, stable, or declined; final findings were adjudicated by the principal investigator. 


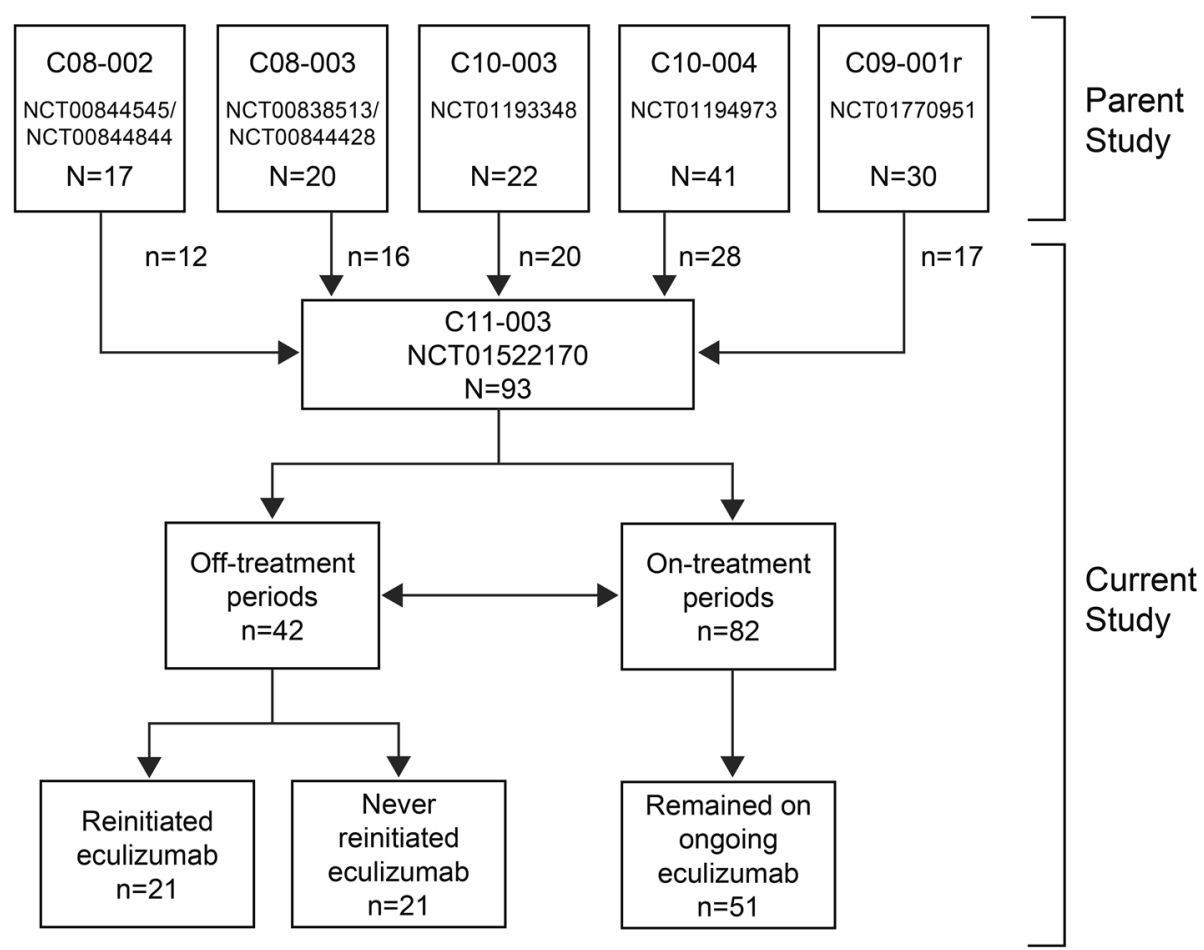

Fig. 1 Patient disposition

Table 1 Definition of TMA manifestation (any one or more listed criteria) [11]

\begin{tabular}{|c|c|}
\hline Type/Severity & Criteria \\
\hline $\begin{array}{l}\text { Laboratory values } \\
\text { change }^{\text {a }}\end{array}$ & $\begin{array}{l}\text { The occurrence of a change in } \geq 2 \text { laboratory values: } \\
\text { - Platelet count decrease } \geq 25 \%^{\mathrm{c}} \text { and }<\mathrm{LLN} \\
\text { - Increase in } \mathrm{SCr} \geq 25 \%^{\mathrm{c}} \text { and }>\text { ULN } \\
\text { - Increase in } \mathrm{LDH} \geq 25 \%^{\mathrm{c}} \text { and }>\text { ULN }\end{array}$ \\
\hline $\begin{array}{l}\text { Clinical signs and } \\
\text { symptoms of TMA }\end{array}$ & $\begin{array}{l}\text { Clinical signs and symptoms considered } \\
\text { definitely related to aHUS, including: } \\
\text { - Thrombosis } \\
\text { - Seizure } \\
\text { - Reduction in renal function } \\
\text { - Proteinuria (new or worse }{ }^{c} \text { and }>1+\text { or }>30 \mathrm{mg} / \mathrm{dL} \text { ) } \\
\text { - Hematuria (new or worse }{ }^{c} \text { and }>50 \mathrm{RBCs} / \mathrm{HPF} \text { ) } \\
\text { - Increased hemolytic anemia } \\
\text { - Biopsy-proven TMA } \\
\text { - Other (eg, extrarenal TMA manifestations, including } \\
\text { confusion, cardiovascular abnormalities, pericarditis, } \\
\text { gastrointestinal symptoms/diarrhea) }\end{array}$ \\
\hline Intervention $^{d}$ & $\begin{array}{l}\text { The patient required PE/PI, dialysis, blood } \\
\text { transfusions, or renal transplant due to a TMA } \\
\text { manifestation }\end{array}$ \\
\hline
\end{tabular}

aHUS atypical hemolytic uremic syndrome; HPF high-powered field; $L D H$ lactate dehydrogenase; LLN lower limit of normal; PE/PI plasma exchange/ plasma infusion; $R B C S$ red blood cells; $S C r$ serum creatinine; TMA thrombotic microangiopathy; ULN upper limit of normal

${ }^{a}$ As determined by changes in laboratory parameters with ongoing follow-up ${ }^{b}$ Measurements were required to be confirmed by a second measurement $\geq 28$ days apart with no interruption

'During each on period, compared with the last laboratory value during the preceding off period. During each off period, compared with the last value during the preceding on period

${ }^{d}$ As determined at the discretion of the investigator
Serious targeted TEAEs were predefined as incidence of serious infection, meningococcal infection, sepsis, leukopenia, infusion reactions, hepatic impairment, and malignancy.

\section{Results}

\section{Patient disposition}

At the final data cutoff on March 30, 2017, a total of 93 patients (26 children/adolescents, 67 adults) were enrolled in the study (Fig. 1). Of these, 82 patients had on-treatment periods during the current study. Overall, 51 patients (55\%; 22 children/adolescents, 29 adults) remained on eculizumab throughout the current study, while 42 (45\%; 17 children/adolescents, 25 adults) had at least one off-treatment period. Twenty-one patients (50\%) who discontinued eculizumab later reinitiated treatment. Reasons for reinitiation included TMA or renal impairment $(n=11)$, preparation for a kidney transplant $(n=5)$, short discontinuation period due to change in dose or missed doses $(n=2)$, administrative reasons $(n=2)$, and multiple serious AEs and a change in dosing $(n=1)$.

\section{Patient characteristics}

Baseline patient characteristics at entry into the parent studies are presented in Table 2. Overall, 55 patients (59\%) had an identified genetic or autoimmune complement abnormality. Compared with patients who 
Table 2 Demographic and baseline clinical characteristics in the parent studies

\begin{tabular}{|c|c|c|c|c|}
\hline \multirow[t]{2}{*}{ Characteristic } & \multirow{2}{*}{$\begin{array}{l}\text { Never Discontinued } \\
(n=51)\end{array}$} & \multicolumn{2}{|c|}{ Discontinued $(n=42)$} & \multirow{2}{*}{$\begin{array}{l}\text { All Patients } \\
(N=93)\end{array}$} \\
\hline & & $\begin{array}{l}\text { Reinitiated } \\
(n=21)\end{array}$ & $\begin{array}{l}\text { Not Reinitiated } \\
(n=21)\end{array}$ & \\
\hline Age, at first eculizumab dose, median (range), years & $23.0(0.0,63.0)$ & $21.0(0.0,65.0)$ & $30.0(0.0,80.0)$ & $21.0(0.0,80.0)$ \\
\hline Age < 12 years, $n(\%)$ & $15(29)$ & $5(24)$ & $6(29)$ & $26(28)$ \\
\hline Female, n (\%) & $30(59)$ & $11(52)$ & $16(76)$ & $57(61)$ \\
\hline Genetic or autoimmune complement abnormality, $\mathrm{n}(\%)^{\mathrm{a}}$ & $31(61)$ & $14(67)$ & $10(48)$ & $55(59)$ \\
\hline \multicolumn{5}{|l|}{ No. of TMA manifestations prior to first eculizumab dose, n (\%) } \\
\hline 1 & $30(59)$ & $13(62)$ & $16(76)$ & $59(63)$ \\
\hline$\geq 2$ & $21(41)$ & $8(38)$ & $5(24)$ & $34(37)$ \\
\hline $\begin{array}{l}\text { Time from most recent TMA manifestation to the first eculizumab dose, } \\
\text { median (range), months }\end{array}$ & $1.8(0.0,47.4)$ & $0.4(0.1,37.8)$ & $0.6(0.0,19.2)$ & $0.9(0.0,47.4)$ \\
\hline Time from aHUS diagnosis to first eculizumab dose, median (range), months & $18.0(0.0,313.3)$ & $3.0(0.0,191.4)$ & $0.5(0.0,178.1)$ & $4.0(0.0,313.3)$ \\
\hline $\begin{array}{l}\text { No. of PE/PI sessions at latest TMA manifestation before the first eculizumab } \\
\text { dose, median (range) }\end{array}$ & $13.0(0.0,230.0)$ & $7.0(0.0,121.0)$ & $7.0(0.0,64.0)$ & $10.5(0.0,230.0)$ \\
\hline Patients with dialysis at baseline of parent study, n (\%) & $18(35)$ & $11(52)$ & $9(43)$ & $38(41)$ \\
\hline Patients with renal transplant prior to first eculizumab dose, n (\%) & $14(28)$ & $4(19)$ & $5(24)$ & $23(25)$ \\
\hline
\end{tabular}

aHUS atypical hemolytic uremic syndrome; CFB complement factor $\mathrm{B}$; $C F H$ complement factor $\mathrm{H}$; CFI complement factor l; $M C P$ membrane cofactor protein; $P E / P I$ plasma exchange/plasma infusion; TMA thrombotic microangiopathy

ancludes pathogenic variants in $C 3, C D 46(M C P), C F B, C F H$, and CFI, as well as CFH autoantibodies as determined at enrollment in parent studies

discontinued eculizumab and did not reinitiate, patients who reinitiated eculizumab trended toward being younger (median 21 vs 30 years of age at first eculizumab dose), male ( $76 \%$ vs $52 \%$ female), treated sooner following the most recent TMA manifestation (median 0.4 vs 0.6 months), diagnosed for a longer time period before parent study entry (median 3.0 vs 0.5 months), having more prior TMA manifestations ( $38 \%$ vs $24 \%$ with $\geq 2$ manifestations), and being more likely to have genetic or autoimmune complement abnormalities (67\% vs $48 \%$ ) (Table 3).

\section{Follow-up and eculizumab exposure}

Duration of eculizumab therapy and follow-up time by treatment status is presented in Additional file 1: Table S1. The median (range) of follow-up overall (parent and long-term follow-up studies combined) was 65.7 (9.9, 102.2) months ( $>5$ years). The duration of eculizumab treatment prior to the first discontinuation was 19.6 $(0.2,86.9)$ months and time to reinitiation was $4.7(0.7$, 69.3) months. Patients who reinitiated eculizumab after discontinuation had an overall exposure of 56.3 (1.3, 91.3) months.

\section{TMA manifestations}

During the study, three TMA manifestations occurred in two patients $(2 \%)$ during on-treatment periods and 14 TMA manifestations occurred in 10 patients (24\%) during off-treatment periods (Table 4). The rate of TMA manifestations was 1.0 per 100 patient-years during on-treatment periods and 13.5 per 100 patient-years during
Table 3 Genetic and autoimmune complement abnormalities in patients in the study

\begin{tabular}{|c|c|c|c|}
\hline \multirow{2}{*}{$\begin{array}{l}\text { Complement } \\
\text { Abnormality by } \\
\text { Risk Level, }{ }^{\mathrm{a}} \mathrm{n}(\%)\end{array}$} & \multirow{2}{*}{$\begin{array}{l}\text { Never Discontinued } \\
(n=51)\end{array}$} & \multicolumn{2}{|c|}{ Discontinued $(n=42)$} \\
\hline & & $\begin{array}{l}\text { Reinitiated } \\
(n=21)\end{array}$ & $\begin{array}{l}\text { Not Reinitiated } \\
(n=21)\end{array}$ \\
\hline High risk & $25(49)$ & $8(38)$ & $6(29)$ \\
\hline $\mathrm{CFH}$ & $14(27)^{\mathrm{b}}$ & $6(29)$ & $3(14)^{c}$ \\
\hline C3 & $6(12)$ & $1(5)$ & $1(5)^{d}$ \\
\hline CFH autoantibodies & $5(10)$ & $1(5)$ & $1(5)$ \\
\hline$C F B$ & $0(0)$ & $0(0)$ & $1(5)$ \\
\hline Low/moderate risk & $6(12)$ & $6(29)$ & $3(14)$ \\
\hline CD46 (MCP) & $3(6)^{e}$ & $3(14)$ & $2(10)$ \\
\hline$C F I$ & $3(6)^{f}$ & $3(14)$ & $1(5)$ \\
\hline Deletions & $0(0)$ & $0(0)$ & $1(5)$ \\
\hline CFHR1, CHFR3 & $0(0)$ & $0(0)$ & $1(5)$ \\
\hline $\begin{array}{l}\text { No identified } \\
\text { abnormality }\end{array}$ & $20(39)$ & $7(33)$ & $11(52)$ \\
\hline
\end{tabular}

CFB complement factor B; CFH complement factor $\mathrm{H}$; CFHR1, CFHR3 complement factor $\mathrm{H}$-related protein 1, complement factor $\mathrm{H}$-related protein 3; CFI complement factor I; MCP membrane cofactor protein

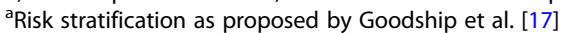

b Includes one patient who also had a CFI mutation, and one patient who also had a CD46 (MCP) mutation

Includes one patient who also had a C3 mutation

dExcludes one patient who also had a CFH mutation

e Includes one patient who also had a CFI mutation. Excludes one patient who also had a CFH mutation

Excludes two patients who also had $C F H$ or CD46 mutations 
Table 4 TMA manifestation rates

\begin{tabular}{|c|c|c|c|c|}
\hline Patient Group/Subgroup & $\begin{array}{l}\text { On-Treatment } \\
\text { Period }\end{array}$ & $\begin{array}{l}\text { Off-Treatment } \\
\text { Period }\end{array}$ & $\begin{array}{l}\text { Fold Change } \\
\text { in Rate }\end{array}$ & $\begin{array}{l}\text { Percent Decrease on } \\
\text { Versus off Treatment }\end{array}$ \\
\hline \multicolumn{5}{|l|}{ Overall } \\
\hline Patients & $n=82$ & $n=42$ & & \\
\hline Patients with TMA, n (\%) & $2(2)$ & $10(24)$ & & \\
\hline Manifestations & 3 & 14 & & \\
\hline Total patient-years & 292.5 & 103.8 & & \\
\hline Rate per 100 patient-years & 1.0 & 13.5 & 13.5 & $93 \%$ \\
\hline \multicolumn{5}{|l|}{ Patients who never discontinued } \\
\hline Patients & $n=51$ & N/A & & \\
\hline Patients with TMA, n (\%) & $2(4)$ & N/A & & \\
\hline Manifestations & 3 & N/A & & \\
\hline Total patient-years & 218.2 & N/A & & \\
\hline Rate per 100 patient-years & 1.4 & N/A & N/A & N/A \\
\hline \multicolumn{5}{|l|}{ Patients who discontinued eculizumab } \\
\hline Patients & $n=31$ & $n=42$ & & \\
\hline Patients with TMA, n (\%) & $0(0)$ & $10(24)$ & & \\
\hline Manifestations & 0 & 14 & & \\
\hline Total patient-years & 74.2 & 103.8 & & \\
\hline Rate per 100 patient-years & 0.0 & 13.5 & N/A & $100 \%$ \\
\hline \multicolumn{5}{|l|}{ Genetic or autoimmune complement abnormality status } \\
\hline Patients with complement abnormality & $n=51$ & $n=24$ & & \\
\hline Patients with TMA, n (\%) & $1(2)$ & $7(29)$ & & \\
\hline Manifestations & 2 & 9 & & \\
\hline Total patient-years & 188.3 & 50.1 & & \\
\hline Rate per 100 patient-years & 1.1 & 18.0 & 16.4 & $94 \%$ \\
\hline Patients without identified complement abnormality & $n=31$ & $n=18$ & & \\
\hline Patients with TMA, n (\%) & $1(3)$ & $3(17)$ & & \\
\hline Manifestations & 1 & 5 & & \\
\hline Total patient-years & 104.1 & 53.7 & & \\
\hline Rate per 100 patient-years & 1.0 & 9.3 & 9.3 & $89 \%$ \\
\hline \multicolumn{5}{|l|}{ Age at diagnosis } \\
\hline Adult patients & $n=41$ & $n=22$ & & \\
\hline Patients with TMA, n (\%) & $0(0)$ & $3(14)$ & & \\
\hline Manifestations & 0 & 5 & & \\
\hline Total patient-years & 140.5 & 56.2 & & \\
\hline Rate per 100 patient-years & 0.0 & 8.9 & N/A & $100 \%$ \\
\hline Pediatric patients ${ }^{\mathrm{b}}$ & $n=41$ & $n=20$ & & \\
\hline Patients with TMA, n (\%) & $2(5)$ & $7(35)$ & & \\
\hline Manifestations & 3 & 9 & & \\
\hline Total patient-years & 152.0 & 47.6 & & \\
\hline Rate per 100 patient-years & 2.0 & 18.9 & 9.5 & $89 \%$ \\
\hline \multicolumn{5}{|l|}{ History of TMA events } \\
\hline Single TMA & $n=51$ & $n=29$ & & \\
\hline Patients with TMA, n (\%) & $2(4)$ & $6(21)$ & & \\
\hline
\end{tabular}


Table 4 TMA manifestation rates (Continued)

\begin{tabular}{|c|c|c|c|c|}
\hline Patient Group/Subgroup & $\begin{array}{l}\text { On-Treatment } \\
\text { Period }\end{array}$ & $\begin{array}{l}\text { Off-Treatment } \\
\text { Period }\end{array}$ & $\begin{array}{l}\text { Fold Change } \\
\text { in Rate }\end{array}$ & $\begin{array}{l}\text { Percent Decrease on } \\
\text { Versus off Treatment }\end{array}$ \\
\hline Manifestations & 3 & 8 & & \\
\hline Total patient-years & 192.7 & 70.4 & & \\
\hline Rate per 100 patient-years & 1.6 & 11.4 & 7.1 & $86 \%$ \\
\hline $\begin{array}{l}\text { Multiple TMA prior to initiation } \\
\text { of eculizumab }\end{array}$ & $n=31$ & $n=13$ & & \\
\hline Patients with TMA, n (\%) & $1(3)$ & $4(31)$ & & \\
\hline Manifestations & 1 & 6 & & \\
\hline Total patient-years & 99.8 & 33.4 & & \\
\hline Rate per 100 patient-years & 1.0 & 18.0 & 18.0 & $94 \%$ \\
\hline \multicolumn{5}{|l|}{ Transplant status } \\
\hline Transplanted kidney & $n=21$ & $n=9$ & & \\
\hline Patients with TMA, n (\%) & $0(0)$ & $0(0)$ & & \\
\hline Manifestations & 0 & 0 & & \\
\hline Total patient-years & 76.0 & 24.3 & & \\
\hline Rate per 100 patient-years & 0.0 & 0.0 & N/A & N/A \\
\hline Native kidney & $n=61$ & $n=33$ & & \\
\hline Patients with TMA, n (\%) & $2(3)$ & $10(30)$ & & \\
\hline Manifestations & 3 & 14 & & \\
\hline Total patient-years & 216.5 & 79.5 & & \\
\hline Rate per 100 patient-years & 1.4 & 17.6 & 12.6 & $92 \%$ \\
\hline
\end{tabular}

N/A not applicable; TMA thrombotic microangiopathy

${ }^{a}$ During off-treatment periods compared with on-treatment periods. ${ }^{b}$ Defined as age $<18$ years at time of diagnosis

off-treatment periods (93\% lower on treatment). All 14 TMA manifestations that occurred during off-treatment periods were reported within the first 30 months following discontinuation. In patients who discontinued eculizumab, there were no TMA manifestations during on-treatment periods, and a rate of 13.5 per 100 patient-years in off-treatment periods.

When stratifying by patient populations (Table 4), rates of TMA during off- versus on-treatment periods were particularly high in pediatric onset patients (18.9 per 100 patient-years), patients with identified genetic or autoimmune complement abnormalities (18.0 per 100 patient-years), and patients with a history of multiple TMAs (18.0 per 100 patient-years). No TMA manifestations were reported in patients with transplanted kidneys, regardless of treatment status.

\section{Kidney function and long-term renal outcomes}

During the first on-treatment period, eculizumab led to a rapid improvement in mean eGFR, which then remained above or near $\approx 60 \mathrm{~mL} / \mathrm{min} / 1.73 \mathrm{~m}^{2}$ during follow-up on treatment (Additional file 1: Figure S1A). In patients who remained on eculizumab treatment throughout the study and were not on chronic dialysis, median eGFR was $24.0 \mathrm{~mL} / \mathrm{min} / 1.73 \mathrm{~m}^{2}$ at baseline and
$59.5 \mathrm{~mL} / \mathrm{min} / 1.73 \mathrm{~m}^{2}$ at last follow-up (Table 5). In this group of patients, dialysis was required by 18 of 51 patients (35\%) at baseline and by $2(4 \%)$ at last follow-up. Patients who discontinued had a higher mean eGFR at the time of discontinuation; over time during follow-up off eculizumab, eGFR slowly decreased but remained > $60 \mathrm{~mL} / \mathrm{min} / 1.73 \mathrm{~m}^{2}$ (Additional file 1: Figure S1B). In this patient subgroup, median eGFR was $12.0 \mathrm{~mL} / \mathrm{min} /$ $1.73 \mathrm{~m}^{2}$ at baseline, $92.3 \mathrm{~mL} / \mathrm{min} / 1.73 \mathrm{~m}^{2}$ at time of discontinuation, and $75.6 \mathrm{~mL} / \mathrm{min} / 1.73 \mathrm{~m}^{2}$ at last follow-up (median [range] follow-up of 31.2 [0.7, 95.1] months; Table 5). Of these patients, dialysis was required by 17 of 35 patients $(48.6 \%)$ at baseline and by 5 of $35(14.3 \%)$ at last follow-up.

Changes in eGFR over time were analyzed for individual patients by treatment status to assess long-term renal outcomes. When comparing long-term kidney function (Table 6), 37 patients (77\%) who remained on eculizumab treatment had improved or stable renal function over time; 11 (23\%) had a decline in kidney function. Overall, 14 of 35 patients (40\%) who discontinued eculizumab had a decline in renal function, including 2 patients (11\%) who discontinued and did not reinitiate eculizumab, and 12 patients (75\%) who discontinued eculizumab and reinitiated treatment. 
Table 5 eGFR and dialysis over follow-up by treatment status

\begin{tabular}{|c|c|c|c|}
\hline & $\begin{array}{l}\text { Never Discontinued } \\
(n=51)\end{array}$ & $\begin{array}{l}\text { Discontinued }^{a} \\
(n=42)\end{array}$ & $\begin{array}{l}\text { All Patients } \\
(N=93)\end{array}$ \\
\hline Patients available for eGFR analysis ${ }^{\mathrm{b}}, \mathrm{n}$ & 39 & 24 & 63 \\
\hline \multicolumn{4}{|l|}{ eGFR prior to first dose of eculizumab in parent study, $\mathrm{mL} / \mathrm{min} / 1.73 \mathrm{~m}^{2}$} \\
\hline Mean (SD) & $30.9(26.9)$ & $29.6(29.1)$ & $30.4(27.5)$ \\
\hline Median (range) & $24.0(8.4,128.3)$ & $12.0(10.0,105.5)$ & $22.1(8.4,128.3)$ \\
\hline \multicolumn{4}{|l|}{ eGFR at time of discontinuation ${ }^{c}, \mathrm{~mL} / \mathrm{min} / 1.73 \mathrm{~m}^{2}$} \\
\hline Mean (SD) & - & $92.4(38.6)$ & - \\
\hline Median (range) & - & $92.3(34.2,181.5)$ & - \\
\hline \multicolumn{4}{|l|}{ eGFR at last follow-up, $\mathrm{mL} / \mathrm{min} / 1.73 \mathrm{~m}^{2}$} \\
\hline Mean (SD) & $65.2(33.1)$ & $85.9(31.8)$ & $73.1(33.9)$ \\
\hline Median (range) & $59.5(14.8,152.2)$ & $75.6(40.0,153.5)$ & $65.7(14.8,153.5)$ \\
\hline Patients on dialysis prior to first dose of eculizumab in parent study, n/N (\%) & 18/51 (35.3) & $17 / 35(48.6)$ & $35 / 86(40.7)$ \\
\hline Patients on dialysis at last follow-up, n/N (\%) & 2/51 (3.9) & $5 / 35(14.3)$ & $7 / 86(8.1)$ \\
\hline
\end{tabular}

eGFR estimated glomerular filtration rate; SD standard deviation

${ }^{a}$ Patients who had eGFR values recorded in the first off-treatment period; includes patients who did and did not reinitiate eculizumab

${ }^{b}$ Excludes patients on chronic dialysis, defined as lasting for $>90$ days without a gap of $>14$ days

'Defined as the last eGFR value before the start of the first off-treatment period in the current study

\section{Safety}

Overall, eculizumab was well tolerated, and the serious targeted TEAEs are shown in Additional file 1: Table S2. Of the reported infections, cases of bacteremia, meningitis, meningococcal infection, pneumococcal infection, mycoplasma pneumonia, and sepsis were determined to be related to eculizumab treatment by the investigators. During the current and parent studies, patients reported three definite and one possible meningococcal infections, but all continued eculizumab and recovered from the infection (Table 7). There were three deaths in the current and parent studies; none were considered related to eculizumab (Table 7).

\section{Discussion}

We have conducted the largest and longest prospective cohort study of eculizumab in aHUS patients, across all age groups. Data from an earlier, interim analysis (cutoff date: March 28, 2015, median exposure, 45.9 months) [11] provided preliminary information on rates of TMA manifestations occurring both off and on eculizumab treatment. Here, we present the final data from this study, providing 2 additional years of follow-up, subgroup analysis that may inform risk profiles, and evaluation of the long-term renal consequences.

In the previous interim analysis [11], TMA manifestations were defined as either clinical signs and symptoms of TMA, interventions, or changes in laboratory values. Although there is no standard definition of TMA, which may be associated with varying degrees of clinical deterioration and outcomes, it is unlikely that changes in single laboratory values are considered to be TMA manifestations by treating clinicians outside of this trial. Thus, in this final analysis, we employed the more stringent definition (ie, excluding TMA defined by changes in a single laboratory criterion) used in the previous interim report [11]. Based on this definition, the rates in this study were 13.5-fold higher during off-treatment periods compared with on-treatment periods, consistent with the interim report.

Ability to identify patients at particular risk for TMA while off treatment would be beneficial for clinicians when

Table 6 Long-term renal outcomes by treatment status

\begin{tabular}{lllll}
\hline Patients, $\mathrm{n}(\%)$ & $\begin{array}{l}\text { Never } \\
\text { Discontinued } \\
(n=48)\end{array}$ & $\begin{array}{l}\text { Discontinued, } \\
\text { Did Not Reinitiate } \\
(n=19)\end{array}$ & $\begin{array}{l}\text { Discontinued } \\
\text { and Reinitiated } \\
(n=16)\end{array}$ & $\begin{array}{l}\text { All Discontinued } \\
(n=35)\end{array}$ \\
\hline Improved & $17(35)$ & $2(11)$ & $0(0)$ & $2(6)$ \\
Stable & $20(42)$ & $15(79)$ & $4(25)$ & $19(54)$ \\
Declined & $11(23)$ & $2(11)$ & $12(75)$ & $14(40)$ \\
\hline
\end{tabular}

Note: For patients who never discontinued eculizumab, estimated glomerular filtration rate (eGFR) was compared at 6 months post-eculizumab initiation and at last follow-up. For patients who discontinued eculizumab, eGFR was compared at the time of discontinuation and at last follow-up. For patients who reinitiated eculizumab, eGFR prior to discontinuation and at last follow-up (post-reinitiation) was compared. Three patients who remained on eculizumab and seven patients who discontinued had missing data and were excluded from this analysis. Individual patient outcomes were assessed independently by the principal investigator and two additional authors. Findings were adjudicated by the principal investigator 
Table 7 Safety events from first dose of eculizumab in parent study

\begin{tabular}{|c|c|c|c|}
\hline Outcome & Sex & Age Category & Description \\
\hline \multirow[t]{4}{*}{$\begin{array}{l}\text { Experienced meningococcal infection } \\
\text { while on eculizumab treatment }\end{array}$} & Female & $20-29$ & $\begin{array}{l}\text { - CFH mutation } \\
\text { - Vaccinated with Mencevax }{ }^{\otimes} \text { (ACYW135), not on prophylactic } \\
\text { antibiotics } \\
\text { - Meningococcal infection serogroup B identified } \\
\text { - Received antibiotics for treatment of infection, which resolved } \\
\text { after } 9 \text { days, and continued on eculizumab }\end{array}$ \\
\hline & Female & $20-29$ & $\begin{array}{l}\text { - CFH mutation, renal transplant } \\
\text { - Vaccinated with Mencevax }{ }^{\oplus} \text { (ACYW135), not on prophylactic } \\
\text { antibiotics } \\
\text { - Meningococcal infection serogroup W135 identified } \\
\text { - Received antibiotics for treatment of infection, which resolved } \\
\text { after } 17 \text { days, and continued on eculizumab }\end{array}$ \\
\hline & Male & $20-29$ & $\begin{array}{l}\text { - No identified complement abnormality at diagnosis; renal transplant } \\
\text { - Vaccinated with Menveo }{ }^{\oplus} \text { (ACYW135), prophylactic antibiotics } \\
\text { - Meningococcal infection serogroup B identified } \\
\text { - Received antibiotics for treatment of infection, which resolved after } \\
10 \text { days, and continued on eculizumab }\end{array}$ \\
\hline & Male & $13-19$ & $\begin{array}{l}\text { - C3 mutation, renal transplant } \\
\text { - Vaccinated with Menactra }{ }^{\oplus} \text {, prophylactic antibiotics } \\
\text { - Clinical presentation was consistent with possible meningococcal } \\
\text { infection (sore throat, knee pain and swelling, skin lesions), but all } \\
\text { blood cultures were negative } \\
\text { - Received antibiotics for treatment of infection, which resolved after } \\
6 \text { days, and continued on eculizumab }\end{array}$ \\
\hline \multirow[t]{3}{*}{ Death $^{\mathrm{a}}$} & Male & $30-39$ & $\begin{array}{l}\text { - C3 mutation, renal transplant, hemorrhagic gastric ulcer s/p gastrotomy } \\
\text { - Had discontinued eculizumab approximately } 6 \text { months prior to death } \\
\text { - Cause of death: Severe intensive care complications and multiorgan } \\
\text { dysfunction secondary to gastrointestinal hemorrhage, lithiasic cholecystitis, } \\
\text { and sepsis }\end{array}$ \\
\hline & Male & $<5$ & $\begin{array}{l}\text { - No complement abnormality identified at diagnosis; } \\
\text { renal failure, respiratory distress, hepatitis, and seizure disorder } \\
\text { - Patient }{ }^{b} \text { experienced abdominal pain, series of infections and bacterial } \\
\text { infection after } 10 \text { months on eculizumab at a reduced dose; had seizures } \\
\text { attributed to metabolic encephalopathy } \\
\text { - Cause of death: Hypoxia due to diffuse alveolar hemorrhage }\end{array}$ \\
\hline & Female & $<5$ & $\begin{array}{l}\text { - No complement abnormality identified at diagnosis; renal and cardiac } \\
\text { failure, pulmonary hypertension, cardiomyopathy } \\
\text { - Was on dialysis at diagnosis and was treated with eculizumab for } \\
2 \text { months but discontinued due to "lack of efficacy" } \\
\text { - Patient experienced a TMA manifestation with multiorgan failure } \\
\text { - Cause of death: Respiratory failure led to cardiac arrest and anoxic brain } \\
\text { injury after being off treatment for } 7 \text { months }\end{array}$ \\
\hline
\end{tabular}

aHUS Atypical hemolytic uremic syndrome, CFH Complement factor $\mathrm{H}$, TMA Thrombotic microangiopathy

${ }^{a}$ No death was considered related to eculizumab

${ }^{\mathrm{b}}$ Patient also described in Additional file 1: Table S2

deciding on long-term management, aiming to reduce risk of TMA relapse. Additional patient enrollment and length of follow-up allowed for evaluation of TMA manifestation rates by patient subgroups, although the study was not specifically designed to facilitate these comparisons. TMA manifestation rates were particularly high off treatment in patients with identified complement genetic or autoimmune abnormalities. These findings are consistent with previous long-term retrospective analyses of the natural history of aHUS in the pre-eculizumab era $[3,12]$ as well as previous prospective and retrospective analyses of eculizumab discontinuation [13-16]. Our current findings also highlight new patient subgroups that may be at particular risk for TMA relapse when taken off treatment, including patients with pediatric onset, and/or those with a history of multiple TMAs. Due to the historically higher mortality rate in pediatric patients and patients diagnosed before adulthood, it is crucial to protect these patients from additional TMA manifestations [3]. When comparing findings from the current analysis to those from a retrospective study of eculizumab discontinuation in a French cohort [15], previous history of multiple TMA manifestations has been consistently identified as a factor of potential importance for TMA risk while off treatment.

Patients with kidney transplants were excluded from the analysis by Fakhouri et al. [15], but TMA events after discontinuation of eculizumab among patients with aHUS following kidney transplants have been reported 
elsewhere [16]. Interestingly, in this study, no TMA manifestations were reported off or on treatment in patients who had transplants. When evaluating profiles of patients with transplants, patients who remained on therapy were more likely to have higher-risk complement abnormalities (ie, $C F H, C F B$, and $C 3$ mutations) and/or multiple history of graft loss. This could suggest that, in this study, transplant patients who discontinued had a lower risk profile overall. Recent guidance from Kidney Disease: Improving Global Outcomes (KDIGO) [17] includes the recommendation that transplant patients, and particularly those with history of previous graft loss, should not discontinue eculizumab because of historically high risk of recurrence and graft loss in the pre-eculizumab era [18]. Data from a case series by Levi et al. [19] document risk of TMA post-eculizumab discontinuation in a transplant patient. However, Duineveld et al. [20] suggest that transplantation in aHUS is possible without prophylactic eculizumab, particularly with living donors, use of lower-dose immunosuppressive regimens, and strict blood pressure control to mitigate endothelial injury. Data from the Global aHUS Registry suggests better outcomes in patients with transplants who initiated eculizumab prior to transplant [21]. Further studies are required for this patient subgroup.

With respect to consequences of TMA and long-term renal outcomes, this study includes the longest-term follow-up (median, 65.7 months of follow up [ie, $>5$ years]) of changes in eGFR ever reported in patients with aHUS. Renal function loss following TMA manifestation was improved with eculizumab, and this improvement was maintained for a median of 74 months ( $>6$ years) of follow-up. At the time of discontinuation, patients who discontinued eculizumab had higher eGFRs than the on-treatment plateau value in patients who never discontinued. Because discontinuation was at the investigators' discretion, we can only speculate as to why this was the case. It may reflect decreased concern regarding risk of TMA in patients with fairly normal kidney function, and a choice was made to discontinue treatment.

We observed a trend toward a decline in kidney function in the group of patients who discontinued eculizumab. This was observed when evaluating the median eGFR over time and, more importantly, when evaluating individual patients during the period when eculizumab was discontinued. Patients who discontinued eculizumab were almost twice as likely to have a decline in kidney function than patients who never discontinued (40\% vs $23 \%$ ) and were less likely to have an improvement in kidney function (6\% vs $35 \%$ ). Because this decline was irrespective of whether a patient had a reported TMA event, it is possible that some patients had "subclinical" TMA activity after eculizumab discontinuation. An analysis of individual patient outcomes in the pediatric patients in this study (Unpublished data, Pape et al., European Society for Paediatric Nephrology, 2018) revealed that after eculizumab discontinuation, some patients maintained renal function but some returned to pre-eculizumab eGFR values, particularly following a TMA event. Perhaps not surprisingly, those patients who reinitiated eculizumab were especially likely to have a decline in kidney function when not receiving eculizumab.

Half of the patients who discontinued eculizumab later reinitiated during the study, mostly due to TMA/renal impairment, or in preparation for a kidney transplant. One patient had multiple serious adverse events and a change in dosing; treatment was reinitiated to salvage his condition, but the patient eventually died during this study. The two patients categorized as "due to change in dose or missed doses" likely would not have been categorized as having discontinued in clinical practice, but were retained in this category based on the definition in the statistical analysis plan of this study. Shifting these two patients to the group of patients who remained on eculizumab based on sensitivity analysis would not have changed outcomes, because no TMA manifestations were reported in these patients.

There were differences between the subgroups of patients who reinitiated eculizumab and those who discontinued eculizumab and never reinitiated therapy. Interestingly, a lower proportion of females reinitiated treatment (52\% of the subgroup) than those who never reinitiated treatment (76\% of the subgroup). Patients who reinitiated treatment were younger and were more likely to have identified complement genetic or autoimmune abnormalities and a history of multiple TMA manifestations, which is similar to the subgroup of patients who never discontinued. Evidence from a pooled, post hoc analysis of the eculizumab clinical trial program in aHUS [22] demonstrated that younger age is among the factors associated with better outcomes on eculizumab. In that analysis, earlier initiation of eculizumab led to improved renal recovery [22]. It is yet to be determined how TMA history before initiation of therapy may affect the disease course after discontinuation.

The safety profile was consistent with those reported in the parent trials [6-9]. Three deaths were reported and were determined to be unrelated to eculizumab treatment. Three definite and one possible meningococcal infections related to eculizumab were reported during this study, and resolved with appropriate antibiotic treatment. The number of meningococcal infections may be related to the sample size in the study, the severity of the patient population included in the trial population [6-9], as well as that the events largely occurred before the more widespread use of antibiotic prophylaxis. A larger post-marketing analysis of safety events and, specifically, meningococcal infections has been performed in all patients treated with eculizumab for paroxysmal nocturnal 
hemoglobinuria and aHUS worldwide. This report provided 10 years of safety information and included a meningococcal infection rate of 0.25 per 100 patient-years, which tended to decrease in frequency over that time period [23]. Clinicians should continue to consult regulatory guidance $[4,5]$ regarding patient counseling of the eculizumab benefit/risk profile, early signs of meningococcal disease, and processes for seeking immediate medical care. The Centers for Disease Control and Prevention has noted that antibiotic prophylaxis is generally considered to be safe, and suggests that clinicians could consider its use for the duration of eculizumab treatment [24].

One limitation of this study is that discontinuation of eculizumab was not done randomly but at the discretion of investigators and patients, and other possible management strategies of aHUS were not evaluated. Hence, the results must be interpreted cautiously. However, it seems likely that patients who were perceived to be at higher risk of TMA would be less likely to discontinue therapy. Changes in dosage were permitted at the investigators' discretion and also were not randomized. Another limitation is that small patient numbers and TMA manifestations prevented robust analysis of patient subgroups. In addition, requirement of serum creatinine level to be both increased by $\geq 25 \%$ and above the upper limit of normal to qualify as a TMA manifestation may have resulted in missed TMA among patients with low muscle mass and low baseline creatinine levels. Finally, identification and validation of sensitive biomarkers of early signs of TMA recurrence may assist in managing these patients long-term for optimal outcomes.

\section{Conclusions}

In summary, this long-term, prospective study confirms the efficacy and safety of eculizumab in the treatment of aHUS, especially as it relates to improvement and maintenance of stable kidney function over 6 years and a very low rate of TMA during that time. Discontinuation of eculizumab was associated with higher risk of TMA and trends toward decreases in renal function over time, despite very high mean eGFR at the time of discontinuation. These findings confirm a similar analysis recently conducted in the patient population enrolled in the Global aHUS Registry [25]. Patient subgroups at the highest potential risk for TMA post-discontinuation were identified and included pediatric disease onset, identified genetic or autoimmune complement abnormalities, and a history of multiple TMAs. Consideration of such risk factors is important during treatment decision-making for patients with aHUS, and close monitoring for signs of TMA and rapid reinitiation of treatment at early signs of TMA is needed for patients who discontinue eculizumab therapy. Under these conditions, discontinuation of eculizumab with careful monitoring may be an option for select patients with aHUS.

\section{Additional file}

Additional file 1: Table S1. Follow-up by treatment status. Table S2. Serious targeted TEAEs during current study. Figure S1A and B. Effects on renal function based on eGFR.

\section{Abbreviations \\ aHUS: Atypical hemolytic uremic syndrome; CFB: Complement factor B; CFH: Complement factor H; CFHR1, CFHR3: Complement factor H-related protein 1, complement factor $\mathrm{H}$-related protein 3; CFI: Complement factor I; eGFR: Estimated glomerular filtration rate; HPF: High-powered field: KDIGO: Kidney Disease: Improving Global Outcomes; LDH: Lactate dehydrogenase; LLN: Lower limit of normal; N/A: Not applicable; PE/ PI: Plasma exchange/plasma infusion; RBC: Red blood cell; SCr: Serum creatinine; SD: Standard deviation; TEAE: Treatment-emergent adverse event; TMA: Thrombotic microangiopathy; ULN: Upper limit of normal}

\section{Acknowledgments}

The sponsor and investigators thank the patients and their families for their participation in and support for this clinical study. The authors would like to acknowledge Peloton Advantage, LLC, an OPEN Health company, which provided medical writing and editorial support by Kristen W. Quinn, PhD, with funding from Alexion Pharmaceuticals, Inc.

\section{Funding}

Role of the funding source.

Alexion Pharmaceuticals, Inc., was responsible for the collection, management, and analysis of information contained in the C11-003 Long-term Follow-up study. Alexion Pharmaceuticals, Inc., contributed to data interpretation, preparation, review, and approval of the manuscript for submission. All authors had full access to all the data in the study and had final responsibility for the decision to submit for publication. Medical writing and editorial support were provided by Peloton Advantage, LLC, an OPEN Health company (Parsippany, NJ), and funded by Alexion Pharmaceuticals, Inc.

\section{Availability of data and materials}

Qualified academic investigators may request participant-level, de-identified clinical data and supporting documents (statistical analysis plan and protocol) pertaining to this study. Further details regarding data availability, instructions for requesting information, and our data disclosure policy will be available on the Alexion.com website (https://alexion.com/research-development).

\section{Authors' contributions}

$J M, Y D, F F, C L, E E M, F P, E R, N S S, L E W$, and LAG created and designed the study and developed the protocol, recruited patients and collected data, analyzed and interpreted the data, and wrote the manuscript. ÅL and JW created and designed the study and developed the protocol, analyzed and interpreted the data, and wrote the manuscript. All authors read and approved the final manuscript.

\section{Ethics approval and consent to participate}

All patients and/or parents/guardians provided written informed consent before entry into the current study. Ethics approvals have been obtained by institutional review boards or ethics committees in participating institutions as follows:

Australia: Alice Springs Hospital, Central Australian HERC, Alice Springs; Royal Adelaide Hospital, SAH HREC / CALHN (CEC), Royal Adelaide HREC (LEC), Adelaide; Austria: Medizinische Universitaet Innsbruck, Ethikkommission der Medizinischen Unitversität Innsbruck, Innsbruck; Medical University Graz Division of Pediatric Nephrology, Ethikkommission der Medizinischen Unitversität Innsbruck, Graz; Belgium: CHU de Liège, Comité d'Ethique Hospitalo-Facuitarire Universitaire de Liège (707) (CEC), Liege; UZ Gent Dienst Nefrologie, Comité d'Ethique Hospitalo-Facuitarire Universitaire de Liège (707) (CEC) UZ Gent Ethisch Comité (LEC), Gent; Canada: Centre Hospitalier Universitaire (CHU) Sainte-Justine, Comité d'éthique de la Recherche CHU Sainte-Justine (LEC), Montreal; The Hospital for Sick Children, The Hospital for Sick Children REB, Toronto; University Health Network, University Health Network REB, Toronto; France: Hôpital Pasteur - CHU de Nice Pole Urologie - Néphrologie, CNOM, CNIL, CCTIRS, Nice; CHU de Bordeaux Pellegrin, CNOM, CNIL, CCTIRS, Bordeaux; Hôpital Robert Debré, Service de Néphrologie 
Pédiatrique, CNOM, CNIL, CCTIRS, Paris; Le Kremlin Bicetre Hospital, Nephrology Unit, CNOM, CNIL, CCTIRS, Le Kremlin Bicetre; Hôpital Edouard Herriot, CNOM, CNIL, CCTIRS, Lyon; CHU de Nantes-Hôpital, Hotel Dieu - Nephro-Greffe (Nephrology), CNOM, CNIL, CCTIRS, Nantes; CHU de Caen Service de Néphrologie Hôpital Clémenceau, CNOM, CNIL, CCTIRS, Caen; Hôpital Bretonneau, IRC Transplantation Rénale, CNOM, CNIL, CCTIRS, Tours; Hôpital de Bois Guillaume-CHU de Rouen, CNOM, CNIL, CCTIRS, Rouen Cedex; CHU St. Etienne-Hôpital Nord, CNOM, CNIL, CCTIRS, Saint Priest En Jarez; Nouvel Hôpital Civil, CNOM, CNIL, CCTIRS, Strasbourg; CHRU de Lille-Hôpital A. Calmette (Nephrologie), CNOM, CNIL, CCTIRS, Lille; Hôpital Tenon, CNOM, CNIL, CCTIRS, Paris; Centre Hospitalier Inter-Communal de Cornouaille, CNOM, CNIL, CCTIRS, Quimper; Hôpital de la Timone Enfants, Unité de Néphrologie, Service de Pédiatrie Multidisciplinaire, CNOM, CNIL, CCTIRS, Marseille; CHU-CH Charles Nicolle Pavillon de Pédiatrie, CNOM, CNIL, CCTIRS, Rouen; Service de Néphrologie/Hémodialyse, CHR Orléans, CNOM, CNIL, CCTIRS, Orleans; Germany: Medizinische Klinik II - Nephrologie und Klinische Immunologie, Ethik-Kommission an der Medizinischen Fakultät (LEC), Aachen; Hannover University Clinic Adult Nephrology, Medizinische Hochschule Hannover Ethikkomission Vorsitzender (LEC), Hannover; Hannover University Clinic Pediatric Nephrology Medizinische Hochschule Hannover Ethikkomission Vorsitzender (LEC). Hannover; Universitaet Heidelberg, Ethik-Kommission der Medizinischen Fakultät Heidelberg (LEC), Heidelberg; Italy: Fondazione IRCCS Ca Granda, Ospedale Maggiore Policlinico, The IRCCS (Italian Research Hospital) Ca' Granda Foundation, Ospedale Maggiore General Hospital (LEC), Milano; Azienda Ospedaliero-Universitaria Careggi, Comitato Etico dell'Azienda OspedalieroUniversitaria Careggi (LEC), Firenze; A.O. Papa Giovanni XXIII, Comitato di Bioetica Azienda Ospedali Riuniti di Bergamo (CEC), Bergamo; Istituto Giannina Gaslini, Istituto Giannina Gaslini Ethics Committee for Scientific Biomedical Research (LEC), Genova; Ospedale dei Bambini G. di Cristina, Arnas Civico di Cristina Benfratelli Comitato di Bioetica (LEC), Palermo; Netherlands: Academic Center Amsterdam (AMC), Dept. Nephrology / Dept. Pediatric Nephrology Stichting CGR (CEC), Amsterdam; University Medical Center Nijmegen (UMCN), St. Radboud Dept. Nephrology / Dept. Pediatrics, Stichting CGR (CEC), Nijmegen Radboud University Medical Center, Stichting CGR (CEC), Nijmegen; Sweden: Karolinska Institutet, Karolinska University Hospital - Huddinge, Regionala Etikprövningsnämnden i Stockholm, Stockholm; Switzerland: INSELSPITAL Universitaetsklinik fuer Kinderheilkunde, Kindernephrologie, Kantonale Ethikkommission Bern (KEK) (LEC), Bern; United Kingdom: Exeter Kidney Unit, Royal Devon and Exeter Hospital (Wonford), NRES Committee South West - Cornwall \& Plymouth (CEC), Royal Devon \& Exeter NHS Foundation Trust (R\&D), Exeter; Great Ormond Street Hospital NRES Committee South West - Cornwall \& Plymouth (CEC), UCL Institute of Child Health / Great Ormond Street Hospital for Children NHS Foundation Trust (R\&D) London; Newcastle Upon Tyne Hospitals NHS Foundation Trust, NRES Committee South West - Cornwall \& Plymouth (CEC), Newcastle upon Tyne Hospital NHS Foundation Trust (R\&D), Newcastle upon Tyne; Clinical Apheresis Unit, Level 1, Beatson WoSCC Gartnavel General Hospital, NRES Committee South West - Cornwall \& Plymouth (CEC), Greater Glasgow \& Clyde Health Board (R\&D), Glasgow; City Hospital, Nottingham University Hospitals NHS Trust, NRES Committee South West - Cornwall \& Plymouth (CEC), Nottingham University Hospitals NHS Trust (R\&D), Nottingham; United States: Driscoll Children's Kidney Center, Driscoll Children's Hospital IRB, Corpus Christi, TX; Fort Wayne Medical Oncology and Hematology, WIRB (Western IRB - central IRB), Fort Wayne, IN; Arthur James Cancer Hospital, WIRB (Western IRB - central IRB), Columbus, OH; Weill Cornell Medical College, Weill Cornell Medical College IRB, New York, NY; Fox Valley Hematology, Affinity IRB, Oshkosh, Wl; Emory Healthcare-Children's Center, Emory IRB, Atlanta, GA; Cincinnati Children's Hospital, CCHMC IRB, Cincinnati, OH; Providence Sacred Heart Medical Center \& Children's Hospital, IRB Spokane, Spokane, WA; Children's Memorial Hospital, Ann \& Robert H. Lurie Children's Hospital of Chicago IRB, Chicago, IL; Westchester Oncology / Hematology Group (New York Medical College Committee for Protection of Human Subjects), Hawthorne, NY; Methodist Hospital (TMHRI IRB), Houston, TX; Children's Hospital Boston, Boston Children's Hospital IRB, Boston, MA; University of Utah School of Medicine Pediatric Pharmacology Program, University of Utah IRB, Salt Lake City, UT; Dunwoody Pediatrics \& Children's Healthcare of Atlanta, WIRB (Western IRB central IRB), Dunwoody and Atlanta, GA; Seattle Children's Hospital, Seattle Children's Hospital IRB, Seattle, WA; Children's Hospital at Montefiore, Albert Einstein College of Medicine IRB, Bronx, NY; Henry Ford Health System, Henry Ford Health System IRB, Detroit, Ml; Vanderbilt University Medical Center, Vanderbilt University IRB, Nashville, TN; Duke University Medical Center, Duke University Health System IRB, Durham, NC. Written informed consent was obtained from all participants.

\section{Consent for publication}

Not applicable.

\section{Competing interests}

JM has received lecture and/or advisory fees from Alexion Pharmaceuticals, Inc., AstraZeneca, Berlin-Chemie, Daiichi Sankyo, Boehringer Ingelheim, and Novartis. YD has received fees from Alexion Pharmaceuticals, Inc., for participation in a symposium and from Sanofi-Ablynx for participation in advisory boards. FF has received fees for participation in advisory boards, experts' meetings, and/or teaching courses from Alexion Pharmaceuticals, Inc. CL has received grant/research support and/or consultancy fees from Achillion Pharmaceuticals, Inc., Alexion Pharmaceuticals, Inc., and CSL Behring; has received honoraria from Alexion Pharmaceuticals, Inc. and CSL Behring; has submitted patents for CSL Behring and Finnegan, Henderson, Farabow, Garrett \& Dunner; is a member of the Editorial Boards for Kidney International, Nephrology Dialysis Transplantation, and Pediatric Nephrology; is a Steering Committee Member of the Alport Syndrome Treatments and Outcomes Registry (ASTOR) and Member of the Safety Board of the European Treatment Trial for Alport Syndrome (EARLY PRO-TECT); is the aHUS International Registry Scientific Advisory Board Chair and HUS International Chair for Alexion Pharmaceuticals, Inc:; and has participated in the Eculizumab in Adolescent Patients With Plasma Therapy-Resistant aHUS (C08-002; NCT00844844), Eculizumab in Adolescent Patients With Plasma Therapy-Sensitive aHUS (C08-003; NCT00844428), and Eculizumab in Pediatric Patients With Atypical Hemolytic-Uremic Syndrome (C10-003; NCT01193348) clinical studies for Alexion Pharmaceuticals, Inc. $\AA \mathrm{L}$ is an employee and stockholder of Alexion Pharma GmbH, Zurich, Switzerland. EEM has participated in the C10-004 adult interventional study (NCT01194973) and in the C11-003 observational, follow-up study (NCT01522170) of atypical hemolytic uremic syndrome patients for Alexion Pharmaceuticals, Inc. FP has received honoraria from Alexion Pharmaceuticals, Inc. ER has received fees for participation in advisory boards, experts' meetings, and/or teaching courses from Alexion Pharmaceuticals, Inc. NSS has received research funding from GlaxoSmithKline plc. JW is an employee and stockholder of Alexion Pharmaceuticals, Inc. LEW has received fees for participation in advisory boards from Alexion Pharmaceuticals, Inc. LAG has received research funding for Emory University from Alexion Pharmaceuticals, Inc., for his participation in the Eculizumab in Pediatric Patients and aHUS International Registry clinical studies; has received grant/research support and/or consultancy fees from AbbVie Inc., Alexion Pharmaceuticals, Inc., Bristol-Myers Squibb, Advicenne Pharmaceuticals, Mallinckrodt Pharmaceuticals, Otsuka America Pharmaceutical, Inc., and Vifor Pharma; has served as a member of a scientific advisory board for Alexion Pharmaceuticals, Inc., and as a member of data safety monitoring boards for Retrophin, Inc. and Relypsa Pharmaceuticals.

\section{Publisher's Note}

Springer Nature remains neutral with regard to jurisdictional claims in published maps and institutional affiliations.

\section{Author details}

${ }^{1}$ Department of Nephrology and Hypertension, Klinik für Nieren- und Hochdruckerkrankungen, Carl Neuberg Str. 1, 30625 Hannover, Germany. ${ }^{2}$ Service de Néphrologie Transplantation Dialyse, CHU de Bordeaux, Place Amélie Raba Léon, CEDEX 33076 Bordeaux, France. ${ }^{3}$ Department of Nephrology and Immunology, UMR 643, CHU de Nantes, 27 Rue la Pérouse, CEDEX 144000 Nantes, France. ${ }^{4}$ Division of Nephrology, The Hospital for Sick Children, 555 University Avenue, Toronto, Ontario M5G 1X8, Canada. ${ }^{5}$ Alexion Pharma GmbH, Giesshübelstrasse 30, 08045 Zurich, Switzerland. 'Department of Nephrology, Niguarda Hospital, Piazza Ospedale Maggiore 3, 20162 Milan, Italy. 'Department of Nephrology, CHU de Lille, 2 Avenue Oscar Lambret, 59000 Lille, France. ${ }^{8}$ Urgences Néphrologiques et Transplantation Rénale, Hôpital Tenon, AP-HP, 4 Rue de la Chine, 75020 Paris, France. ${ }^{9}$ Sorbonne Université, 15-21 Rue de l'École de Médecine, Paris 75006, France. ${ }^{10}$ Institute of Cellular Medicine, University of Newcastle upon Tyne, 4th Floor, William Leech Building, Newcastle upon Tyne NE2 4HH, UK. ${ }^{11}$ Alexion Pharmaceuticals, Inc., 121 Seaport Boulevard, Boston, MA 02210, USA. ${ }^{12}$ Néphrologie-Transplantation, CHU de Liège, Sart-Tilman B35, 04000 Liège, Belgium. ${ }^{13}$ Division of Pediatric Nephrology, Emory University School of Medicine and Children's Healthcare of Atlanta, 2015 Uppergate Drive NE, Atlanta, GA 30322, USA. 
Received: 19 December 2018 Accepted: 27 March 2019

Published online: 10 April 2019

\section{References}

1. Fakhouri F, Zuber J, Fremeaux-Bacchi V, Loirat C. Haemolytic uraemic syndrome. Lancet. 2017;390:681-96.

2. Campistol JM, Arias M, Ariceta G, Blasco M, Espinosa L, Espinosa M, Grinyo JM, Macia M, Mendizabal S, Praga M, Roman E, Torra R, Valdes F, Vilalta R, Rodriguez de Cordoba S. An update for atypical haemolytic uraemic syndrome: diagnosis and treatment. A consensus document. Nefrologia. 2015:35:421-47.

3. Fremeaux-Bacchi V, Fakhouri F, Garnier A, Bienaime F, Dragon-Durey MA, Ngo S, Moulin B, Servais A, Provot F, Rostaing L, Burtey S, Niaudet P, Deschenes G, Lebranchu Y, Zuber J, Loirat C. Genetics and outcome of atypical hemolytic uremic syndrome: a nationwide French series comparing children and adults. Clin J Am Soc Nephrol. 2013;8:554-62.

4. US Food and Drug Administration. Soliris (eculizumab) [prescribing information]. Boston, MA: Alexion Pharmaceuticals, Inc.; 2018.

5. European Medicines Agency. Soliris (eculizumab) [summary of product characteristics]. Paris: Alexion Europe SAS; 2017.

6. Legendre CM, Licht C, Muus P, Greenbaum LA, Babu S, Bedrosian C, Bingham C, Cohen DJ, Delmas Y, Douglas K, Eitner F, Feldkamp T, Fouque D, Furman RR, Gaber O, Herthelius M, Hourmant M, Karpman D, Lebranchu Y, Mariat C, Menne J, Moulin B, Nurnberger J, Ogawa M, Remuzzi G, Richard T, Sberro-Soussan R, Severino B, Sheerin NS, Trivelli A, Zimmerhackl LB, Goodship T, Loirat C. Terminal complement inhibitor eculizumab in atypical hemolytic-uremic syndrome. N Engl J Med. 2013;368:2169-81.

7. Licht C, Greenbaum LA, Muus P, Babu S, Bedrosian CL, Cohen DJ, Delmas Y, Douglas K, Furman RR, Gaber OA, Goodship T, Herthelius M, Hourmant M, Legendre CM, Remuzzi G, Sheerin N, Trivelli A, Loirat C. Efficacy and safety of eculizumab in atypical hemolytic uremic syndrome from 2-year extensions of phase 2 studies. Kidney Int. 2015;87:1061-73.

8. Greenbaum LA, Fila M, Ardissino G, Al-Akash SI, Evans J, Henning P, Lieberman KV, Maringhini S, Pape L, Rees L, van de Kar N, C.A.J., Vande Walle J, Ogawa M, Bedrosian CL, Licht C. Eculizumab is a safe and effective treatment in pediatric patients with atypical hemolytic uremic syndrome. Kidney Int 2016;89:701-11.

9. Fakhouri F, Hourmant M, Campistol JM, Cataland SR, Espinosa M, Gaber AO, Menne J, Minetti EE, Provot F, Rondeau E, Ruggenenti P, Weekers LE, Ogawa M, Bedrosian CL, Legendre CM. Terminal complement inhibitor eculizumab in adult patients with atypical hemolytic uremic syndrome: a single-arm, open-label trial. Am J Kidney Dis. 2016;68:84-93.

10. Vilalta R, Al-Akash S, Davin J, Diaz J, Gruppo R, Hernandez J, Jungraithmayr T, Langman C, Lapeyraque A, Macher M, Rodig N, Sherbotie J, Sherwinter J, Simonetti G, Smith J, Thornburg C, Wuhl E. Eculizumab therapy for pediatric patients with atypical hemolytic uremic syndrome: efficacy and safety outcomes of a retrospective study [abstract 1155]. Haematologica. 2012; 97(suppl 1):479.

11. Menne J, Delmas Y, Fakhouri F, Kincaid JF, Licht C, Minetti EE, Mix C, Provot F, Rondeau E, Sheerin NS, Wang J, Weekers LE, Greenbaum LA. Eculizumab prevents thrombotic microangiopathy in patients with atypical haemolytic uraemic syndrome in a long-term observational study. Clin Kidney J. 2018. [Epub ahead of print].

12. Noris M, Caprioli J, Bresin E, Mossali C, Pianetti G, Gamba S, Daina E, Fenili C, Castelletti F, Sorosina A, Piras R, Donadelli R, Maranta R, van der Meer I, Conway EM, Zipfel PF, Goodship TH, Remuzzi G. Relative role of genetic complement abnormalities in sporadic and familial aHUS and their impact on clinical phenotype. Clin J Am Soc Nephrol. 2010;5:1844-59.

13. Ardissino G, Possenti I, Tel F, Testa S, Salardi S, Ladisa V. Discontinuation of eculizumab treatment in atypical hemolytic uremic syndrome: an update. Am J Kidney Dis. 2015;66:172-3.

14. Ardissino G, Testa S, Possenti I, Tel F, Paglialonga F, Salardi S, Tedeschi S, Belingheri M, Cugno M. Discontinuation of eculizumab maintenance treatment for atypical hemolytic uremic syndrome: a report of 10 cases. Am J Kidney Dis. 2014;64:633-7.

15. Fakhouri F, Fila M, Provot F, Delmas Y, Barbet C, Chatelet V, Rafat C, Cailliez M, Hogan J, Servais A, Karras A, Makdassi R, Louillet F, Coindre JP, Rondeau E, Loirat C, Fremeaux-Bacchi V. Pathogenic variants in complement genes and risk of atypical hemolytic uremic syndrome relapse after eculizumab discontinuation. Clin J Am Soc Nephrol. 2017;12:50-9.
16. Wijnsma KL, Duineveld C, Volokhina EB, van den Heuvel LP, van de Kar N, Wetzels JFM. Safety and effectiveness of restrictive eculizumab treatment in atypical haemolytic uremic syndrome. Nephrol Dial Transplant. 2018;33:635-45.

17. Goodship TH, Cook HT, Fakhouri F, Fervenza FC, Fremeaux-Bacchi V, Kavanagh D, Nester CM, Noris M, Pickering MC, Rodriguez de Cordoba S, Roumenina LT, Sethi S, Smith RJ. Atypical hemolytic uremic syndrome and C3 glomerulopathy: conclusions from a "Kidney Disease: Improving Global Outcomes" (KDIGO) Controversies Conference. Kidney Int. 2017;91:539-51.

18. Le Quintrec M, Zuber J, Moulin B, Kamar N, Jablonski M, Lionet A, Chatelet V, Mousson C, Mourad G, Bridoux F, Cassuto E, Loirat C, Rondeau E, Delahousse M, Fremeaux-Bacchi V. Complement genes strongly predict recurrence and graft outcome in adult renal transplant recipients with atypical hemolytic and uremic syndrome. Am J Transplant. 2013;13:663-75.

19. Levi C, Fremeaux-Bacchi V, Zuber J, Rabant M, Devriese M, Snanoudj R, Scemla A, Amrouche L, Mejean A, Legendre C, Sberro-Soussan R. Midterm outcomes of 12 renal transplant recipients treated with eculizumab to prevent atypical hemolytic syndrome recurrence. Transplantation. 2017;101:2924-30.

20. Duineveld C, Verhave JC, Berger SP, van de Kar N, Wetzels JFM. Living donor kidney transplantation in atypical hemolytic uremic syndrome: a case series. Am J Kidney Dis. 2017;70:770-7.

21. Siedlecki AM, Isbel N, Vande Walle J, James Eggleston J, Cohen DJ. Eculizumab use for kidney transplantation in patients with a diagnosis of atypical hemolytic uremic syndrome. Kidney Int Rep. 2018;4(3):434-46.

22. Vande Walle J, Delmas Y, Ardissino G, Wang J, Kincaid JF, Haller H. Improved renal recovery in patients with atypical hemolytic uremic syndrome following rapid initiation of eculizumab treatment. J Nephrol. 2017;30:127-34.

23. Socie G, Caby-Tosi MP, Marantz JL, Cole JA, Bedrosian CL, Gasteyger C, Mujeebuddin A, Hillmen P, Vande Walle J, Haller H. Eculizumab in paroxysmal nocturnal haemoglobinuria and atypical haemolytic uraemic syndrome: 10-year pharmacovigilance analysis. Br J Haematol. 2019. [Epub ahead of print]

24. McNamara LA, Topaz N, Wang X, Hariri S, Fox L, MacNeil JR. High risk for invasive meningococcal disease among patients receiving eculizumab (soliris) despite receipt of meningococcal vaccine. MMWR Morb Mortal Wkly Rep. 2017;66:734-7.

25. Ariceta G, Ardissino G, Sartz L, Fakhouri F, Gasteyger C, Al-Dakkak I. Thrombotic microangiopathy frequency in patients with atypical HUS: discontinuing vs remaining on eculizumab treatment [abstract FR-OR017]. J Am Soc Nephrol. 2018;29:44.

Ready to submit your research? Choose BMC and benefit from:

- fast, convenient online submission

- thorough peer review by experienced researchers in your field

- rapid publication on acceptance

- support for research data, including large and complex data types

- gold Open Access which fosters wider collaboration and increased citations

- maximum visibility for your research: over $100 \mathrm{M}$ website views per year

At BMC, research is always in progress.

Learn more biomedcentral.com/submissions 